\title{
Hemophagocytic Lymphohistiocytosis and Inflammatory Bowel Disease: Case Report and Systematic Review
}

\author{
Bárbara Brambilla ${ }^{a}$ Amanda Machado Barbosa ${ }^{a}$ Cassiano da Silva Scholze ${ }^{b}$ \\ Floriano Riva ${ }^{b}$ Lislene Freitas ${ }^{c}$ Raul Angelo Balbinot ${ }^{c}$ Silvana Balbinot ${ }^{c}$ \\ Jonathan Solderac \\ ${ }^{a}$ Faculty of Medicine, Universidade de Caxias do Sul, Caxias do Sul, Brazil; ${ }^{b}$ Pathologist, CPM Laboratório de Caxias \\ do Sul, Caxias do Sul, Brazil; ' ${ }^{C}$ Clinical Gastroenterology, Universidade de Caxias do Sul, Caxias do Sul, Brazil
}

\section{Keywords \\ Lymphohistiocytosis, hemophagocytic · Inflammatory bowel diseases - Crohn's disease - Colitis, ulcerative · Thionucleosides}

\begin{abstract}
Aim: To report a case of a female patient with hemophagocytic lymphohistiocytosis (HLH) and to systematically review the available cases of the association between $\mathrm{HLH}$ and inflammatory bowel disease (IBD). Methods: In accordance to Preferred Reporting Items for Systematic Reviews and MetaAnalysis guidelines, retrieval of studies was based on Medical Subject Headings and Health Sciences Descriptors, which were combined using Boolean operators. Searches were run on the electronic databases Scopus, Web of Science, MEDLINE (PubMed), Biblioteca Regional de Medicina, Latin American and Caribbean Health Sciences Literature, Cochrane Library for Systematic Reviews and Opengrey.eu. Languages were restricted to English, Spanish and Portuguese. There was no date of publication restrictions. The reference lists of the studies retrieved were searched manually. Results: The search strategy retrieved 223 references. In the final analysis, 28 references were included, with the report of 35 cases. The
\end{abstract}

most common clinical finding was fever, $57 \%$ of patients had a cytomegalovirus infection and 30 patients were on thiopurines previously to HLH diagnosis. Most patients were treated with steroids and antiviral therapy. All-cause mortality was $22 \%$. Conclusion: These findings suggest that there might be a connection of $\mathrm{HLH}$ to IBD, opportunistic viral infections and the use of thiopurines. Due to the severity of such disease, the clinical suspicion is paramount to early diagnosis and therapy.

(C) 2020 The Author(s) Published by S. Karger AG, Basel

\section{Introduction}

Hemophagocytic lymphohistiocytosis (HLH) is a rare and severe systemic syndrome characterized by a rapidly progressive generalized inflammatory response associated with the release of pro-inflammatory cytokines and the

ORCID number: Bárbara Brambilla (0000-0003-4993-4122), Amanda Machado Barbosa (0000-0002-0040-3577), Cassiano da Silva Scholze (0000-0002-3403-5506), Lislene Freitas (0000-0002-4220-4613), Raul Angelo Balbinot (0000-0003-4705-0702), Silvana Sartori Balbinot (0000-0002-5026-1028), Jonathan Soldera (0000-0001-6055-4783).

\begin{tabular}{ll}
\hline KARGER & ( 2020 The Author(s) Karger \\
& Published by S. Karger AG, Basel Open access \\
karger@karger.com & This article is licensed under the Creative Commons Attribution- \\
www.karger.com/iid & NonCommercial-NoDerivatives 4.0 International License (CC BY- \\
NC-ND) (http://www.karger.com/Services/OpenAccessLicense). \\
Usage and distribution for commercial purposes as well as any dis- \\
tribution of modified material requires written permission.
\end{tabular}

Jonathan Soldera, MSc

Clinical Gastroenterology, School of Medicine, Universidade de Caxias do Sul Av. Vereador Mário Pezzi, 699/601

Caxias do Sul 95084-180 (Brazil)

jonathansoldera@gmail.com 
Table 1. HLH 2004 diagnostic criteria [37]

The diagnosis of HLH can be established if one of either 1 or 2 below is fulfilled:

1. Molecular identification of an HLH-associated gene mutation (e.g., PRF1, UNC13D, STX11, STXBP2, Rab27A, SH2D1A, BIRC4, LYST, ITK, SLC7A7, XMEN, HPS).

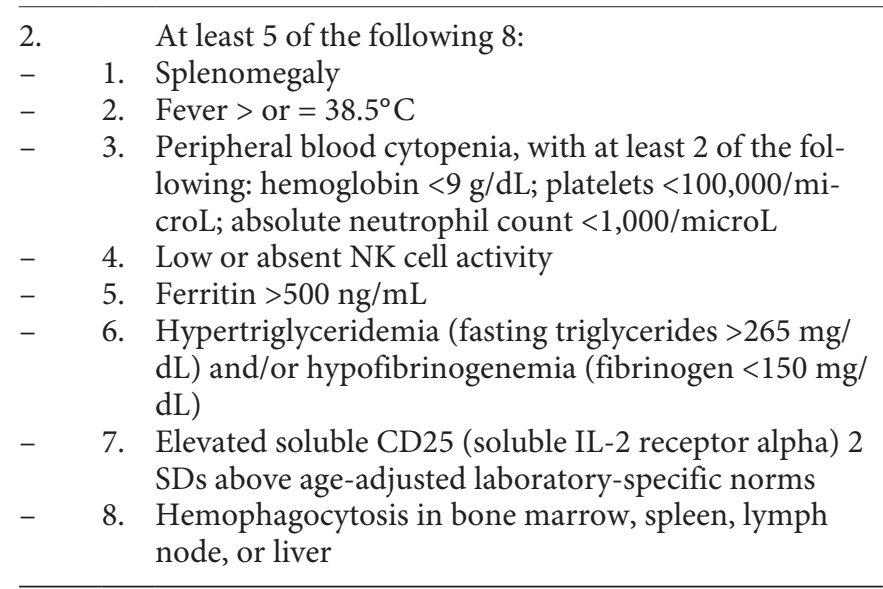

HLH, hemophagocytic lymphohistiocytosis.

activation of the immune system. It can be mistaken for sepsis due to similar clinical characteristics [1]. Thus, HLH is a differential diagnosis to be considered in cases of multiple system organ failure in the presence of hepatosplenomegaly and pancytopenia.

Terms are used to describe HLH and related syndromes. Primary HLH is caused by a gene mutation, which can be one of the familial HLH loci or in a gene responsible for one of several immunodeficiency syndromes. Primary HLH is also called familial HLH [2]. The term secondary HLH, also called sporadic or acquired HLH, is used to describe patients without a known familial mutation and who typically have a trigger for developing acute HLH [2]. Although viruses are the most common triggering factors for HLH, other triggering factors are bacteria, fungi, and parasites. Examples of viral triggering factors are herpesvirus (Epstein-Barr virus [EBV], Cytomegalovirus [CMV], VHH8, HSV), HIV, HTLV, hepatitis virus (A, B and C), measles, mumps, rubella, adenovirus, dengue, hantavirus, parvovirus B19, enterovirus and influenza [3]. Macrophage activation syndrome is a form of secondary HLH that occurs in patients with autoimmune diseases [4]. The most frequent are systemic juvenile idiopathic arthritis, followed by systemic lupus erythematosus, Kawasaki disease and juvenile dermatomyositis [5]. In addition to autoimmune triggers, other factors like tumors especially lymphomas, transplants, drugs, pregnancy, vaccines, surgery and hemodialysis can lead to secondary HLH [3].

Since the disease is difficult to diagnose, criteria have been established for this purpose. The diagnostic criteria of HLH are shown in Table 1. Clinical and laboratory manifestations of HLH include fever, splenomegaly, cytopenias, hypertriglyceridemia, hyperferritinemia, hemophagocytosis, diminished NK cell activity, coagulopathy, liver dysfunction and also neurologic dysfunction. The syndrome usually is treated with immunosuppressants, allogeneic hematopoietic stem cell transplantation and etoposide [6].

It has been described in the literature several cases of association between HLH and inflammatory bowel disease (IBD). These cases occur mostly in patients with infections by opportunistic pathogens, while using immunosuppressive agents [7].

The aim of this paper is to report a case of a female woman with IBD diagnosed with HLH and to systematically review available cases of this association.

\section{Case Report}

Female patient, 37-year old, previously diagnosed with ulcerative colitis (UC) in 2015, Montreal type E1, using oral mesalamine in remission since the diagnosis. She was admitted to the emergency department due to recurrent fever $\left(39-40{ }^{\circ} \mathrm{C}\right)$, chills, malaise, asthenia, nausea, weight loss and liquid diarrhea. On physical exam, she had abdominal pain in the right hypochondrium and genital lesions compatible with herpes.

A colonoscopy was performed due to the suspicion of UC exacerbation, which showed multiple puntiform and superficial ulcers, with flat borders, from caecum to rectum. The mucosa was normal between ulcers. This was suggestive of ischemic ulcers. Immunochemistry to herpes-virus and CMV were negative. The genital lesions were biopsied and immunochemistry came back positive for herpes infection. The patient began to receive intravenous acyclovir, with improvement of the genital lesions.

During her hospital stay, she presented with an acute acalculous cholecystitis, undergoing urgent video laparoscopic cholecystectomy. The pathological analysis of the gallbladder demonstrated inflammatory infiltrate consisted of neutrophils and eosinophils and epithelial erosion associated with edema and transmural acute inflammatory process (Fig. 1). She was started on piperacillin-tazobactam. Aminotransferase levels were measured on admittance, before and after cholecystectomy, and the results were, respectively, aspartate transaminase 94, 25, and $29 \mathrm{UI} / \mathrm{L}$; alanina transaminase 110, 40, and $37 \mathrm{UI} / \mathrm{L}$; gamma-glutamyl transpeptidase 475, 415, and $413 \mathrm{UI} / \mathrm{L}$. After surgery, she began to present pancytopenia, hyperferritinemia, hypoalbuminemia, high-grade fever, hepatosplenomegaly, ascites and pleural and pericardial effusion. The main diagnostic hypotheses were CMV infection due to immunosuppression, systemic lupus erythematosus and HLH. The results of CMV serology and antinuclear antibody were negative. This raised the clinical value of the diagnosis of HLH. Hence, 

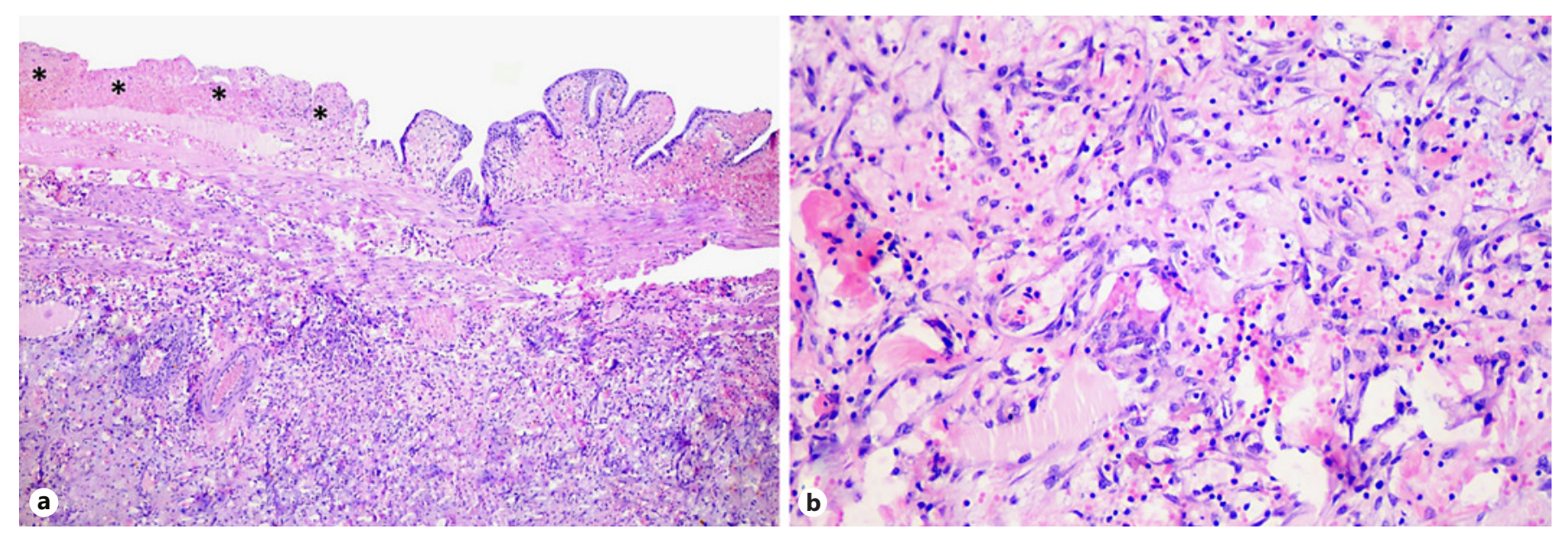

Fig. 1. Gallbladder. a Epithelial erosion associated with edema and transmural acute inflammatory process (haemotoxylin and eosin $40 \times$ ). b Inflammatory infiltrate consisted of neutrophils and eosinophils, (haemotoxylin and eosin $100 \times)$.

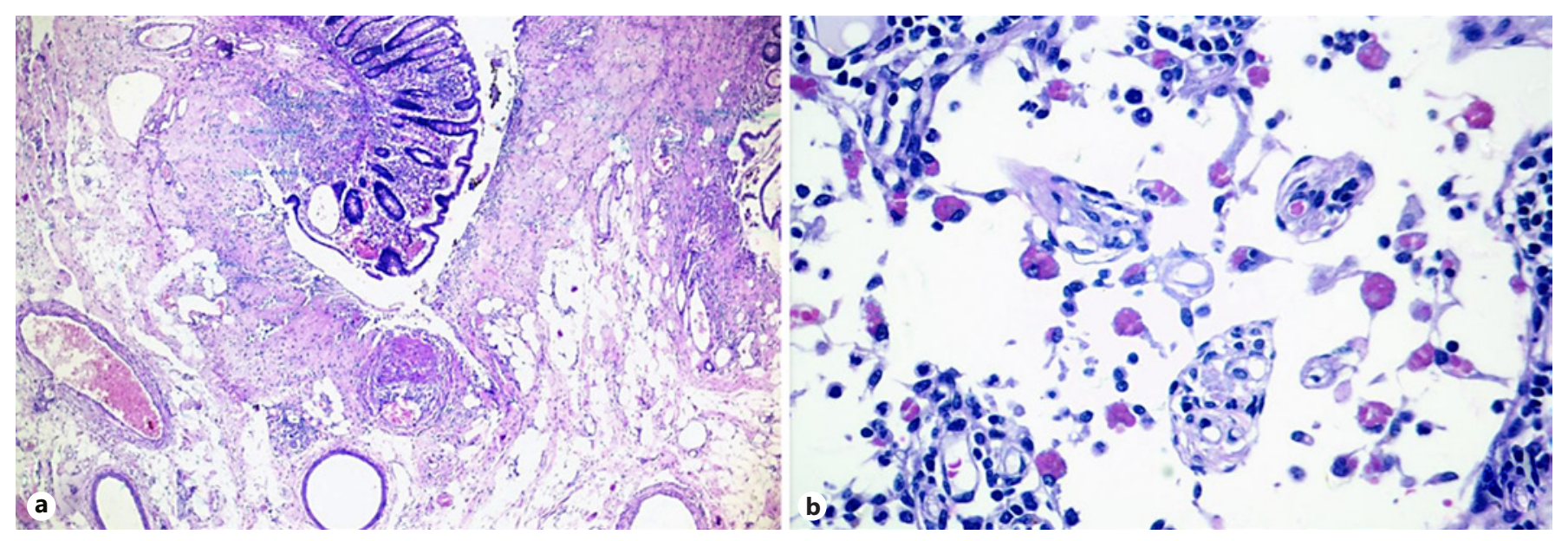

Fig. 2. Colon. a Thrombi in arterioles on colonic wall (haemotoxylin and eosin $40 \times$ ). b Macrophages associated with hemophagocytosis (haemotoxylin and eosin 400×).

a bone marrow biopsy was promptly performed and high dose dexamethasone was started.

While the patient waited for results, she presented spontaneous pneumoperitoneum. An explorative laparotomy was performed and an acute perforation in the caecum was found, motivating a right colectomy with an ileostomy. She was admitted to intensive care unit after surgery and antimicrobial treatment was escalated to meropenem, polymyxin B, anidulafungin, and vancomycin. The patient died shortly afterwards due to a fungal sepsis - Candida $s p$. was isolated in her bloodstream. After her death, the histopathologic analysis of the bone marrow showed hypercellularity ( $80 \%)$ due to granulocytic hyperplasia and the anatomopathological study of the caecum showed retrocecal and mesenteric lymph nodes with macrophages associated with hemophagocytosis inside the sinusoids (Fig. 2), thrombi in arterioles on colonic wall causing ischemic infarction, ulceration and neutrophilic exudate, confirming the suspected diagnosis of HLH. The key aspect to this case is that the HLH presented initially as an UC exacerbation and masked the real causing factor of the HLH, which was the herpes virus infection.

\section{Materials and Methods}

This study was carried out in accordance with the recommendations contained in the Preferred Reporting Items for Systematic Reviews and Meta-Analysis guidelines [8]. Our systematic review was registered with the International Prospective Register of Systematic Reviews, maintained by York University, on May 4, 2019 (registration No. CRD 42019125584 [www.crd.york.ac.uk/prospero/]). 


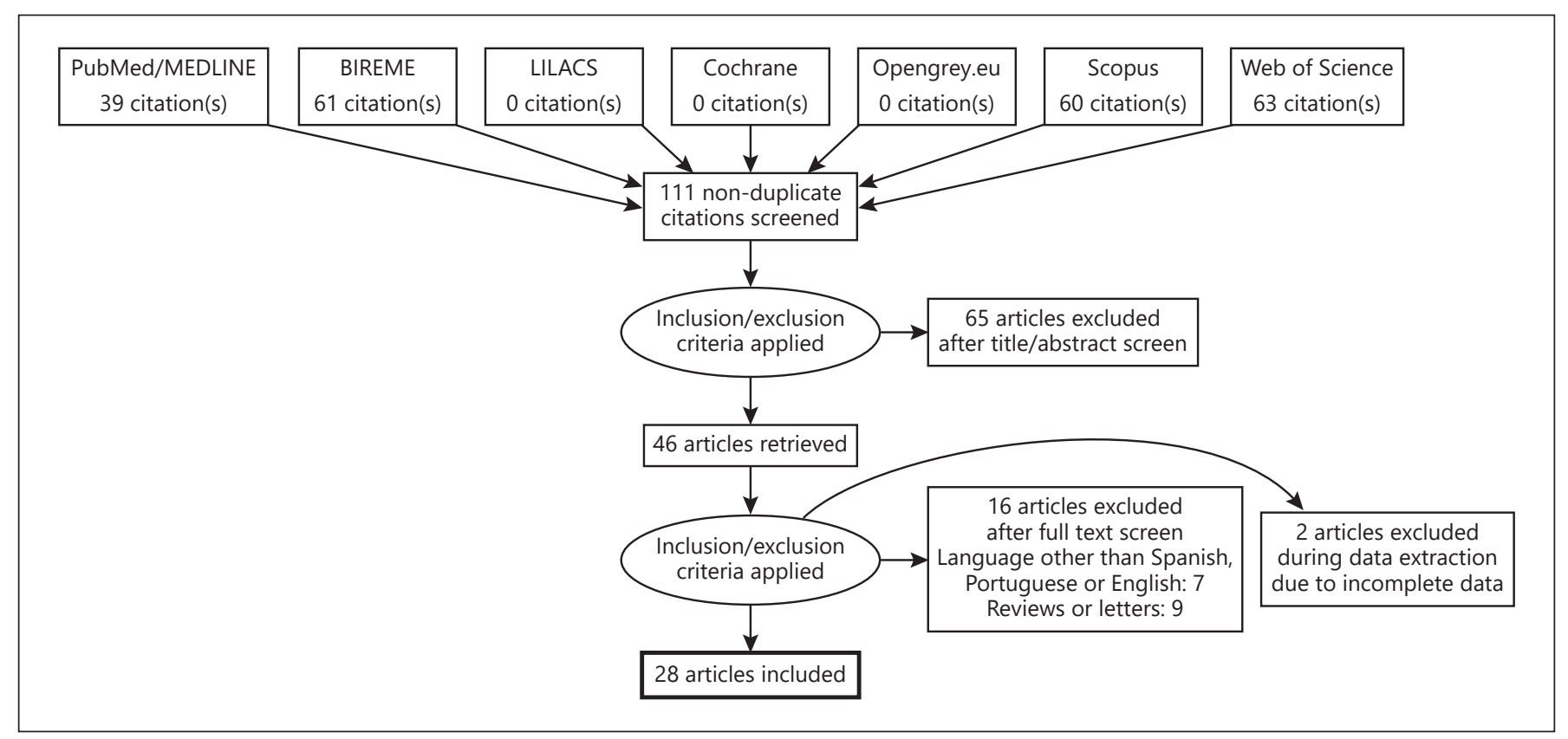

Fig. 3. PRISMA-P flowchart of the systematic review. BIREME, Biblioteca Regional de Medicina; LILACS, Latin American and Caribbean Health Sciences Literature.

\section{Data Sources}

Studies were retrieved using the terms described on Appendix. Searches were run on the electronic databases Scopus, Web of Science, Medline (PubMed), Biblioteca Regional de Medicina, Latin American and Caribbean Health Sciences Literature, Cochrane Library for Systematic Reviews and Opengrey.eu. Languages were restricted to English, Spanish and Portuguese. There was no date of publication restrictions. The reference lists of the retrieved studies were submitted to manual search. Databases were searched in January 2019.

\section{Inclusion Criteria and Outcomes}

Inclusion criteria were clinical case report or case series studies involving HLH and IBD. Exclusion criteria were types of studies other than case reports or case series and articles that were not related to the topic. If there was more than one study published using the same case, the most recent study was selected for the analysis. Studies published only as abstracts were included, as long as the data available made data collection possible. The outcome measured was recovery or death.

\section{Study Selection and Data Extraction}

The search terms used for each database are described in the Appendix. An initial screening of titles and abstracts was the first stage to select potentially relevant papers. Studies that did not address the inclusion criteria were excluded. The second step was the analysis of the full-length papers. In this step, some studies were removed for lack of clinical information. Two independent reviewers (B.B., A.M.B.) extracted data using a standardized data extraction form after assessing and reaching consensus on eligible studies. The same reviewers separately assessed each study and extracted data about the characteristics of the subjects and the out- comes measured. A third party (J.S.) was responsible for divergences in study selection and data extraction, clearing them when required.

\section{Statistical Analysis}

Data was summarized using descriptive analysis - frequency and means. This was calculated using Microsoft Excel.

\section{Results}

\section{Systematic Review}

Using the search strategy, 223 references were found and 112 references were excluded because they were duplicates. After analyzing titles and abstracts, 65 references were excluded and 46 full text papers were analyzed. In the final analysis, 28 references were considered, including 35 cases. A flowchart illustrating the search strategy is shown in Figure 3. Studies included were either a case report or a case series.

Cases from France, Spain, the United States, Australia and Canada were the most common $(22.8,14.2,11.4,8.5$, and $8.5 \%$ respectively). A total of 35 patients were included, corresponding to 22 males (62.8\%) and $13 \mathrm{fe}$ males $(37.1 \%)$. The age ranged from 11 to 77 year-old (mean age was 32 years). Of all patients, 26 (74.2\%) were cases of Crohn's disease and 9 (25.7\%) were cases of UC. 

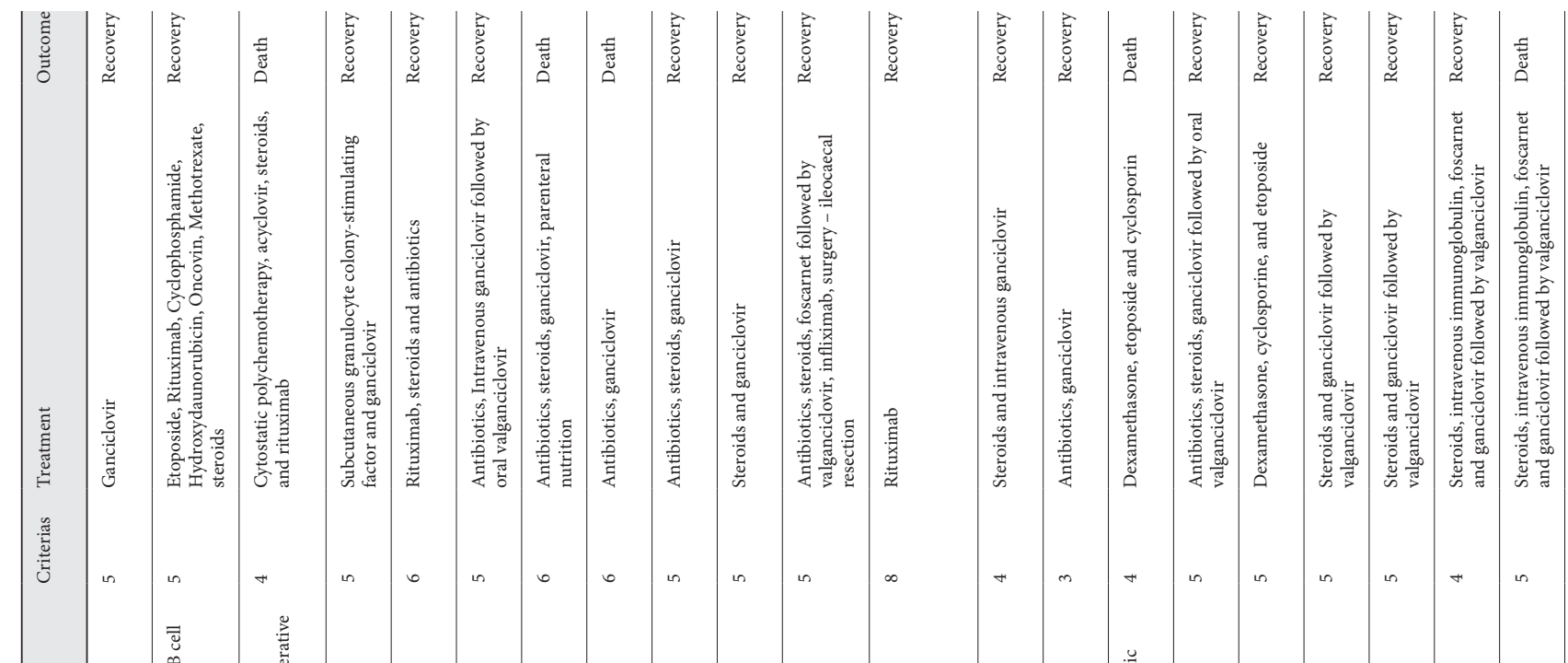

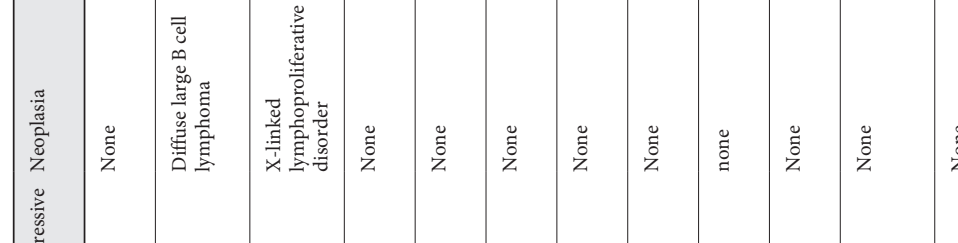

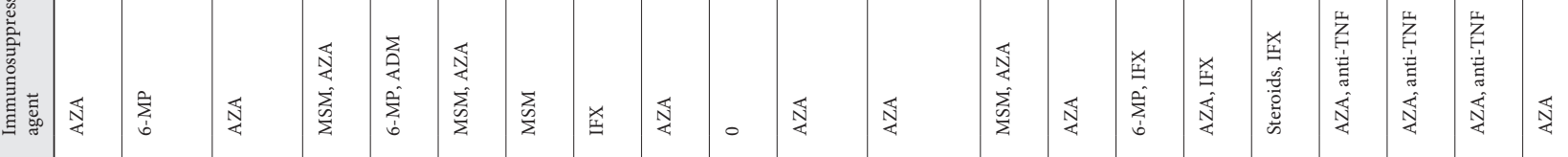

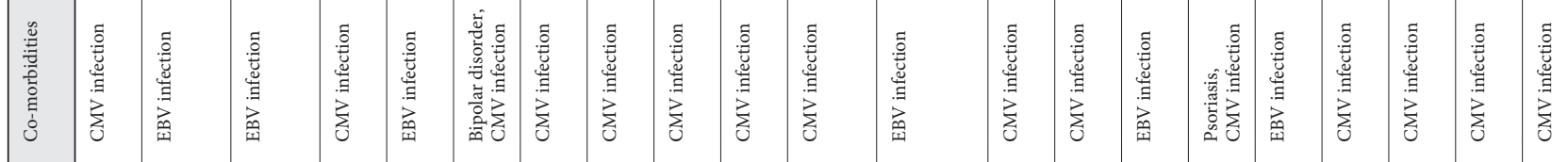
○.

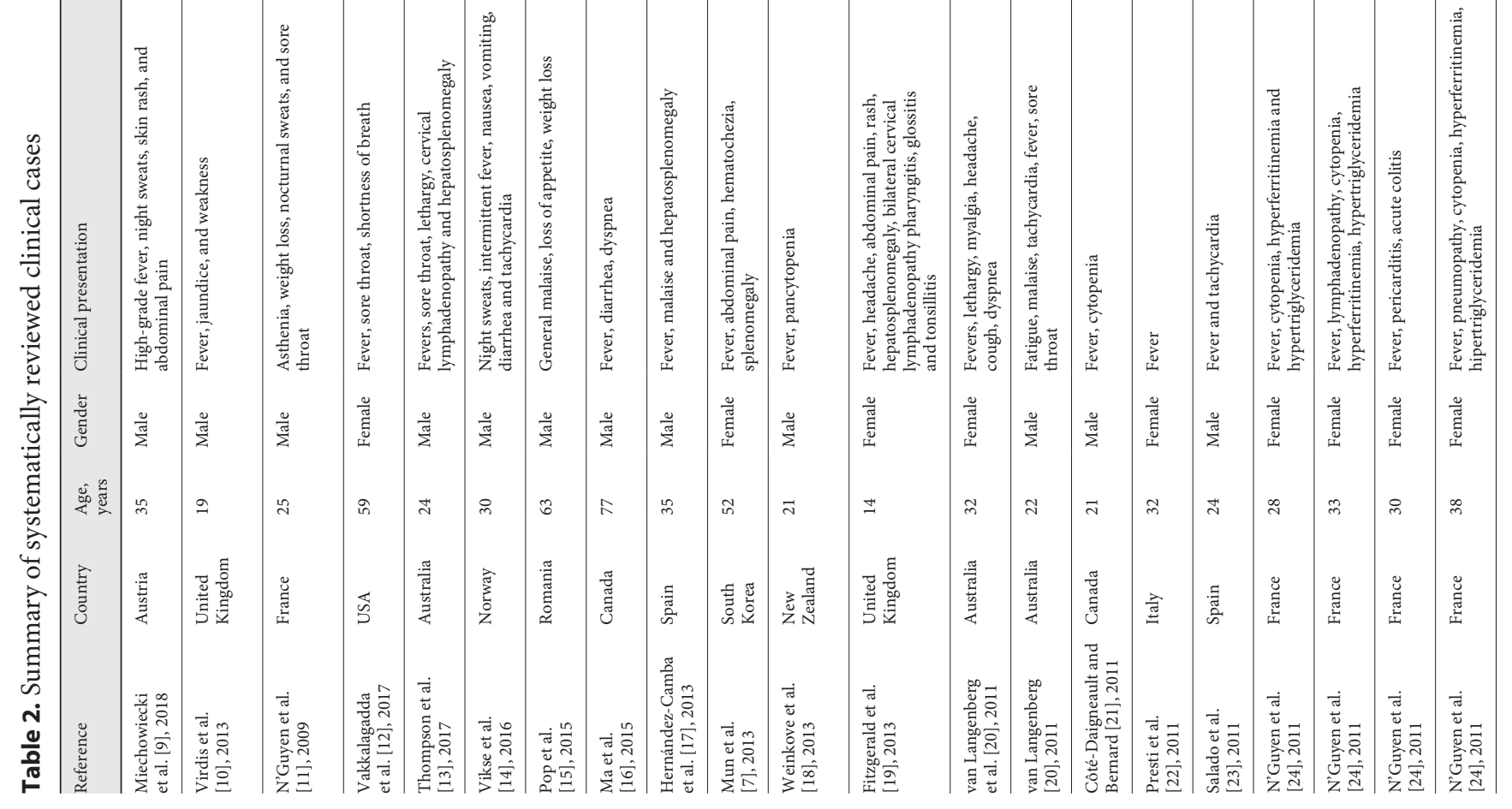




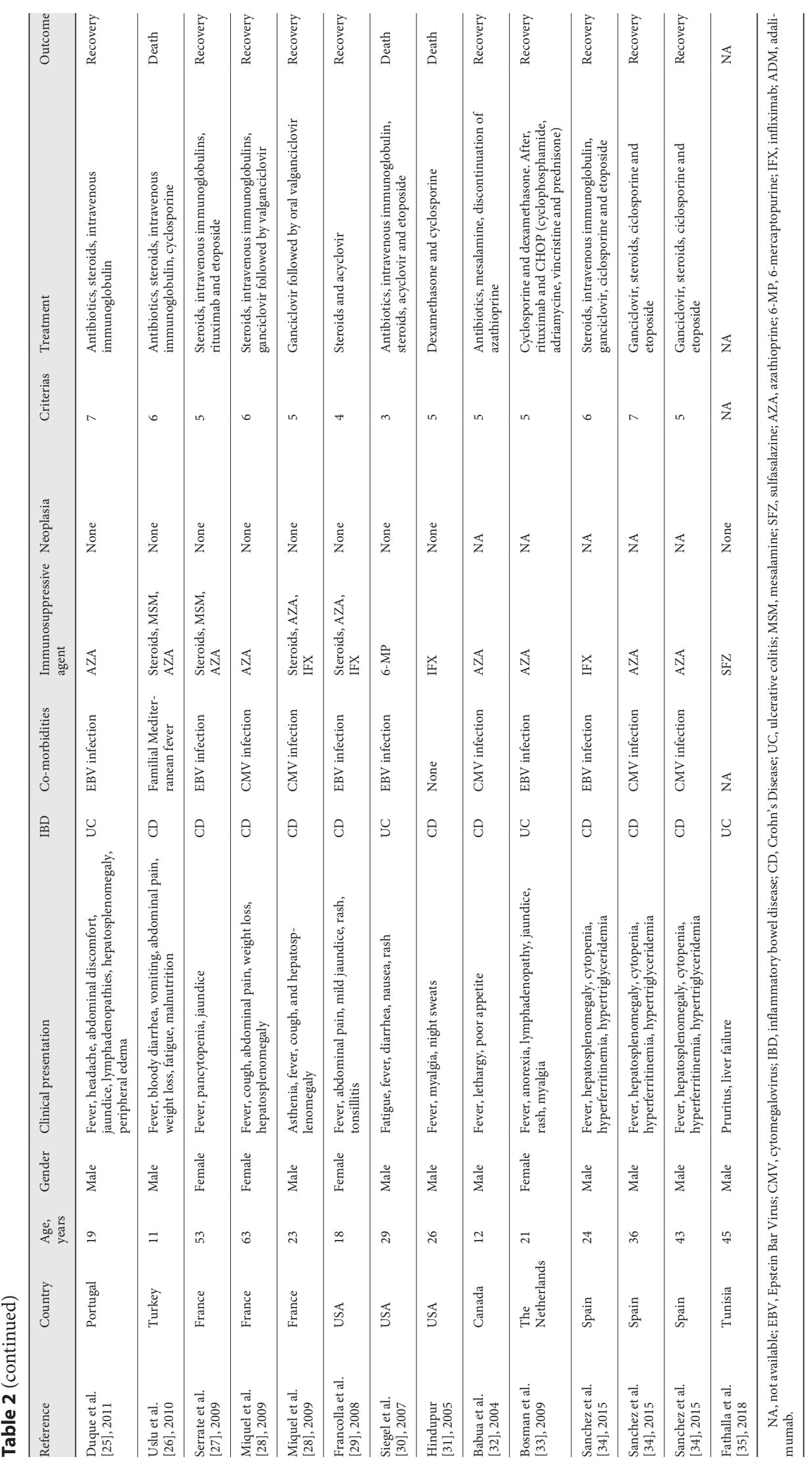


The most common clinical presentation was fever, present in $91.4 \%$ of cases. Hepatosplenomegaly was present in 9 patients $(25.7 \%)$ and just one had isolated splenomegaly.

Opportunistic viral infection was very common. CMV infection was present in $57.1 \%$ of patients, while EBV infection was present in $34.2 \%$ of patients. Three cases had an associated malignancy (8.5\%).

Regarding medication in use, 12 patients were on antiTNF ( 8 on infliximabe and 1 on adalimumab); 30 patients were on thiopurines (24 on azathioprine and 4 on 6-mercaptopurine) and 8 patients were using aminosalicylates ( 6 on mesalamine and 2 on sulfasalazine).

The mean score of the criteria for diagnosing HLH was 5. Most patients were treated with steroids: 26 patients. Antiviral drugs were used in 23 patients (ganciclovir: 18, acyclovir: 3 , and foscarnet: 3 ). Chemotherapy was used in 10 for treatment of HLH. In percentage, the chemotherapy drugs used were $80 \%$ etoposide, $20 \%$ Cyclophosphamide, 20\% Hydroxydaunorubicin. One of the studies does not mention which medication was used.

Regarding outcome, 26 of the cases showed recovery (74.2\%) and 8 patients died (22.8\%). The systematic review findings are summarized on Table 2.

\section{Discussion}

HLH is a rare and life-threatening syndrome known for an excessive inflammatory reaction and tissue destruction [36]. While HLH is considered to be a disease that requires genetic predisposition, viral infections are recognized as its most important triggers, especially CMV and EBV [36]. It is frequently related to immunosuppressive therapy, such as those generally used for the treatment of IBD, post-transplantation patients and other conditions [36].

The main cells involved in HLH are the natural killers cells and macrophages [37]. The pathophysiology consists in an excessive immune activation and inflammation, caused by a failure of the NK cells to eliminate damaged cells as the macrophages, resulting in a lack of the normal down-regulation of macrophages and of lymphocytes activation [37]. The activated macrophages start to phagocyte blood cells, such as platelets, red blood cells, and white blood cells. This might lead to pancytopenia [37].

The hemophagocytosis undergoing inside the blood vessels may cause endothelial injury and thrombi, which leads to ischemia. Therefore, it is not uncommon that pa- tients with HLH develop acute acalculous cholecystitis due to the stasis and concentration of bile salts inside the gallbladder [38]. After the AAC is established, the gallbladder becomes vulnerable to opportunistic infections, such as CMV, Escherichia coli and Cryptosporidium [39]. If not diagnosed and treated soon, it evolves to perforation and generalized peritonitis. The case report is an example of this complication [40].

$\mathrm{HLH}$ is primary an autosomal-recessive disorder of the immune system, and it has been reported with an incidence of 1.2 per 1 million population per year [40]. However, it is more common as a secondary condition [41]. It generally presents itself as a multiple organ disease [42]. The first signs can mimic common infections [41]. It can be frequently mistaken to an exacerbation of a previously diagnosed disease, such as IBD, and hence it can show similar symptoms, such as diarrhea and gastrointestinal bleeding, as presented in Table 1 [42]. However, IBD associated with HLH is rare [43]. There is no data about geographic differences in HLH presentations or outcomes in IBD patients in our region, as it is a predominant region of European immigrants.

Prolonged courses of thiopurines may decrease circulating lymphocytes due to their effect of apoptosis, which is important to HLH [43]. However, they also affect immunological defense, which leads to a predisposition to a viral infection, such as CMV, EBV or varicella zoster virus [43]. The most common clinical features are fever, hepatosplenomegaly, lymphadenopathy, neurologic symptoms (seizures, ataxia, mental status changes and headache) and skin rash [42]. It can also affect pulmonary system, heart and kidneys. These clinical features are described on several of the cases reports presented on Table 2, which confirm the information that they are the most usual clinical presentation of HLH.

The diagnosis is based upon the criteria used in HLH2004 trial, detailed in Table 1 [41]. HLH has also been related to malignancy, especially lymphoid cancers, such as T-cell or natural killer-cell lymphomas, B-cell leukemia, Hodgkin Lymphoma, solid tumors and myeloid malignancies [44]. Some of the cases reported on Table 2 present malignancy during the course of $\mathrm{HLH}$, and also infections, that seem to be a trigger in this case as well: it has been described that patients with lymphoma might demonstrate EBV infection in neoplastic tissue during thiopurine use [45].

Despite the strong association between HLH and EBV infection, EBV testing before therapy with thiopurines is not recommended. EBV is not a sole trigger and 
will not eliminate the risk of HLH [46]. However, according to a large study performed with 1,483 patients over 17 years old, it is important to know the serological status of the patient to avoid a primary EBV infection during thiopurines use [45]. It is very important to also stress that CMV, herpes-virus and EBV infections might mimic IBD exacerbation [47], which can trigger HLH.

In the reported case, the herpetic infection was the actual trigger to activate the macrophages. This, although, is more associated to neonate patients. It is likely that HSV leads to unregulated production of T cells, histiocytes and macrophages due to a cytokine reaction [48]. Similar to HLH, HSV infections might increase the level of serum ferritin. Hyperferritinemia is one of the HLH criteria for diagnosis, but it may be seen in other inflammatory and infectious processes, such as viral infections [49].

Treatment is necessary to control the abnormal activation of NK cells [44]. An early diagnostic is very important to survival. Cessation of immunosuppressive therapy is mandatory [50]. In case of viral infection as a trigger, the antiviral treatment should be promptly initiated [44]. Specific treatment must me initiated as soon as possible. It is generally used an association of high-dose steroids (dexamethasone or methylprednisolone), cyclosporine A and etoposide, in an attempt to control inflammation [47]. If not treated quickly, it can lead to death shortly [44].

In conclusion, HLH is a life-threatening disease that can simulate an IBD exacerbation. It is generally triggered by a viral infection, which can also simulate an IBD exacerbation. It should be promptly suspected in patients with IBD on thiopurines, which develop hepatosplenomegaly and fever, leading to a diagnostic evaluation and immediate treatment.

\section{Acknowledgments}

The authors would like to thank CPM Laboratory for the images of the biopsies.

\section{Statement of Ethics}

A family member of the deceased patient has acquiesced to the reporting of the case. The systematic review has been registered with the International Prospective Register of Systematic Reviews, maintained by York University, on May 4, 2019 (registration no. CRD 42019125584 [www.crd.york.ac.uk/prospe$\mathrm{ro} /])$.

\section{Disclosure Statement}

The authors have nothing to disclose.

\section{Funding Sources}

The authors have funded themselves the work for this paper.

\section{Author Contributions}

All authors contributed to study concept and design, and drafting of the manuscript; all authors contributed to acquisition of data, analysis and interpretation of data. J.S. and B.B. contributed to statistical analysis. J.S. contributed to study supervision. All authors contributed to critical revision of the manuscript for important intellectual content.

\section{Appendix}

\section{Search Strategy}

PubMed:

"Lymphohistiocytosis, Hemophagocytic"(Mesh) AND ("Inflammatory Bowel Diseases"[Mesh] OR "Crohn Disease”[Mesh] OR “Colitis, Ulcerative”[Mesh])

Biblioteca Regional de Medicina:

"Hemophagocytic Lymphohistiocytosis" AND ("Inflammatory Bowel Disease" OR “Crohn's Disease” OR “Ulcerative Colitis")

Latin American and Caribbean Health Sciences Literature:

("Linfohistiocitose Hemofagocítica" OR "Linfohistiocitose Hematofagocítica") AND ("Doença Inflamatória Intestinal" OR "Doença de Crohn" OR "Retocolite Ulcerativa”)

Cochrane Library:

"Hemophagocytic Lymphohistiocytosis" AND ("Inflammatory Bowel Disease” OR “Crohn's Disease” OR “Ulcerative Colitis”)

OpenGrey.eu:

"Hemophagocytic Lymphohistiocytosis" AND ("Inflammatory Bowel Disease" OR “Crohn's Disease” OR "Ulcerative Colitis")

Scopus:

(TITLE-ABS-KEY ["hemophagocytic lymphohistiocytosis"] $A N D$ TITLE-ABS-KEY ["inflammatory bowel disease" OR "Crohn's disease" OR "ulcerative colitis"])

Web of Science
Brambilla/Barbosa/Scholze/Riva/Freitas/ Balbinot/Balbinot/Soldera 


\section{References}

1 Vick EJ, Patel K, Prouet P, Martin MG. Proliferation through activation: hemophagocytic lymphohistiocytosis in hematologic malignancy. Blood Adv. 2017 May;1(12):779-91.

2 La Rosée P, Horne A, Hines M, von Bahr Greenwood T, Machowicz R, Berliner N, Birndt S, et al. Recommendations for the management of hemophagocytic lymphohistiocytosis in adults. Blood. 2019 Jun;133(23):2465-77.

3 Mostaza-Fernández GL, Carriedo UD. Ruiz de Morales JM. Linfohistiocitosis hemofagocítica asociada a infecciones virales: reto diagnóstico y dilema terapéutico. Revista Clínica Española, [s.l.], v. 214, n. 6, p. 320-27, ago. 2014. Elsevier BV. Available from: http://dx doi.org/10.1016/j.rce.2014.03.009.

4 Lerkvaleekul B, Vilaiyuk S. Macrophage activation syndrome: early diagnosis is key. Open Access Rheumatol. 2018 Aug;10:117-28.

5 Lin CI, Yu HH, Lee JH, Wang LC, Lin YT, Yang $\mathrm{YH}$, et al. Clinical analysis of macrophage activation syndrome in pediatric patients with autoimmune diseases. Clin Rheumatol. 2012 Aug;31(8):1223-30.

6 Al-Samkari H, Berliner N. Hemophagocytic Lymphohistiocytosis. Annu Rev Pathol. 2018 Jan;13(1):27-49.

7 Mun JI, Shin SJ, Yu BH, Koo JH, Kim DH, Lee $\mathrm{KM}$, et al. A case of hemophagocytic syndrome in a patient with fulminant ulcerative colitis superinfected by cytomegalovirus. Korean J Intern Med. 2013 May;28(3):352-5.

8 Moher D, Liberati A, Tetzlaff J, Altman DG; PRISMA Group. Preferred reporting items for systematic reviews and meta-analyses: the PRISMA statement. PLoS Med. 2009 Jul 6(7):e1000097.

9 Miechowiecki J, Stainer W, Wallner G, Tuppy $\mathrm{H}$, Aichinger W, Prammer W, et al. Severe complication during remission of Crohn's disease: hemophagocytic lymphohistiocytosis due to acute cytomegalovirus infection. $\mathrm{Z}$ Gastroenterol. 2018 Mar;56(3):259-63.

10 Virdis F, Tacci S, Messina F, Varcada M. Hemophagocytic lymphohistiocytosis caused by primary Epstein-Barr virus in patient with Crohn's disease. World J Gastrointest Surg. 2013 Nov;5(11):306-8.

11 N'guyen Y, Andreoletti L, Patey M, LecoqLafon C, Cornillet P, Léon A, et al. Fatal Epstein-Barr virus primo infection in a 25 -yearold man treated with azathioprine for Crohn's disease. J Clin Microbiol. 2009 Apr;47(4) 1252-4.

12 Vakkalagadda CV, Cadena-Semanate R, Non LR. Cytomegalovirus-Associated Hemophagocytic Syndrome in a 59-Year-Old Woman with Ulcerative Colitis. Am J Med. 2017 Jul;130(7):e305-6.

13 Thompson G, Pepperell D, Lawrence I, McGettigan BD. Crohn's disease complicated by Epstein-Barr virus-driven haemophagocytic lymphohistiocytosis successfully treated with rituximab. BMJ Case Rep. 2017 Feb 2017:bcr2016218578
14 Vikse J, Cacic DL, Carlsen A, Cooper TJ, Grimstad T. A man in his 30s with ulcerative colitis and pancytopenia. Tidsskr Nor Laegeforen. 2016 Jun;136(11):1010-4.

15 Pop CS, Becheanu G, Calagiu D, Jantea PV, Rădulescu DM, Pariza G, et al. A rare complication of CMV infection in Crohn's disease - hemophagocytic syndrome: a case report. Rom J Morphol Embryol. 2015;56(4):1535-40.

16 Ma C, Fedorak RN, Halloran BP. Recurrent Fevers After Infliximab Therapy for Ulcerative Colitis. Gastroenterology. 2016 Jan; 150(1):e1-2.

17 Hernández-Camba A, Lakhwani S, Ramos L, Raya JM, Quintero E. Cytomegalovirus-associated hemophagocytic syndrome in a patient with Crohn's disease receiving azathioprine. J Gastrointestin Liver Dis. 2013 Dec;22(4): 471-2.

18 Weinkove R, Dickson M, Eliadou E, Stace $\mathrm{NH}$, Goossens L, Ferguson P. Fever and pancytopenia in a patient with Crohn's disease. Gut. 2013 Sep;62(9):1327-81.

19 Fitzgerald MP, Armstrong L, Hague R, Russell RK. A case of EBV driven haemophagocytic lymphohistiocytosis complicating a teenage Crohn's disease patient on azathioprine, successfully treated with rituximab. J Crohn's Colitis. 2013 May;7(4):314-7.

20 van Langenberg DR, Morrison G, Foley A, Buttigieg RJ, Gibson PR. Cytomegalovirus disease, haemophagocytic syndrome, immunosuppression in patients with IBD: 'a cocktail best avoided, not stirred'. J Crohn's Colitis. 2011 Oct;5(5):469-72.

21 Côté-Daigneault J, Bernard EJ. Hepatosplenic lymphoma presenting initially as hemophagocytic syndrome in a 21-year-old man with Crohn's disease: a case report and literature review. Can J Gastroenterol. 2011 Aug; 25(8):417-8.

22 Presti MA, Costantino G, Della Torre A, Belvedere A, Cascio A, Fries W. Severe CMVrelated pneumonia complicated by the hemophagocytic lymphohistiocytic (HLH) syndrome in quiescent Crohn's colitis: harmful cure? Inflamm Bowel Dis. 2011 Nov; 17(11):E145-6.

23 Salado CT, Gallego AG, Carnerero EL, De la Cruz Ramírez D, Justiniano JM, Galán JL, et al. Hemophagocytic lymphohistiocytosis in Crohn's disease associated with primary infection by Epstein-Barr virus. Inflamm Bowel Dis. 2011 Nov;17(11):E143-4.

24 N'Guyen Y, Baumard S, Salmon JH, Lemoine L, Lévêque N, Servettaz A, et al. Cytomegalovirus associated hemophagocytic lymphohistiocytosis in patients suffering from Crohn's disease treated by azathioprine: a series of four cases. Inflamm Bowel Dis. 2011 Sep; 17(9):E116-8

25 Duque G, Ferreira R, Figueiredo P, Sousa I, Ferreira M, Fernandes A, et al. Rare cause of fever in a patient with ulcerative colitis. Inflamm Bowel Dis. 2011 Jun;17(6):E64-5.
26 Uslu N, Demir H, Balta G, Saltik-Temizel IN, Ozen H, Gürakan F, et al. Hemophagocytic syndrome in a child with severe Crohn's disease and familial Mediterranean fever. J Crohn's Colitis. 2010 Sep;4(3):341-4.

27 Serrate C, Silva-Moreno M, Dartigues P, Poujol-Robert A, Sokol H, Gorin NC, et al. Epstein-Barr virus-associated lymphoproliferation awareness in hemophagocytic syndrome complicating thiopurine treatment for Crohn's disease. Inflamm Bowel Dis. 2009 Oct;15(10):1449-51.

28 Miquel T, Bonnet DP, Leport J, Longuet P, Bletry O, Leport C. Hemophagocytic syndrome in the course of Crohn's disease: possible association with cytomegalovirus infection. Am J Gastroenterol. 2009 Jan;104(1): 252

29 Francolla KA, Altman A, Sylvester FA. Hemophagocytic syndrome in an adolescent with Crohn disease receiving azathioprine and infliximab. J Pediatr Gastroenterol Nutr. 2008 Aug;47(2):193-5.

30 Siegel CA, Bensen SP, Ely P. Should rare complications of treatment influence decisionmaking in ulcerative colitis? Inflamm Bowel Dis. 2007 Feb;13(2):242.

31 Hindupur S. Hemophagocytosis in hemophagocytic lymphohistiocytosis. Am J Hematol. 2005 Dec;80(4):299-300.

32 Babu TG, Boctor D, Davey A, Bond MC, Jacobson K. Cytomegalovirus-associated hemophagocytic syndrome in a child with Crohn disease receiving azathioprine. J Pediatr Gastroenterol Nutr. 2004 Oct;39(4):41821.

33 Bosman G, Langemeijer SM, Hebeda KM, Raemaekers JM, Pickkers P, van der Velden $\mathrm{WJ}$. The role of rituximab in a case of EBVrelated lymphoproliferative disease presenting with haemophagocytosis. Neth J Med. 2009 Sep;67(8):364-5

34 Sanchez Y, Trigo C, Marquez C, Leo E, Marquez L. Hemophagocytic lymphohistiocytosis in Crohn's Disease associated to citomegalovirus (CMV) or Epstein-Barr virus (EBV). J Crohn's Colitis. 2015;9(Suppl 1):S128.

35 Fathalla N. Ouni1 B, Larif S, Saii A, Hmouda H, Slim R, Ben Salem C. Sulfasalazine-Induced Dress Complicated by Hemophagocytic Lymphohistiocytosis in an Adult Ulcerative Colitis Patient. Drug Saf. 2018;41(11):1188.

36 Henter JI, Elinder G, Söder O, Ost A. Incidence in Sweden and clinical features of familial hemophagocytic lymphohistiocytosis. Acta Paediatr Scand. 1991 Apr;80(4):428-35.

37 Filipovich A, McClain K, Grom A. Histiocytic disorders: recent insights into pathophysiology and practical guidelines. Biol Blood Marrow Transplant. 2010 Jan;16(1 Suppl):S82-9.

38 Wang AJ, Wang TE, Lin CC, Lin SC, Shih SC. Clinical predictors of severe gallbladder complications in acute acalculous cholecystitis. World J Gastroenterol. 2003 Dec;9(12):28213. 
39 Wind P, Chevallier JM, Jones D, Frileux P, Cugnenc PH. Cholecystectomy for cholecystitis in patients with acquired immune deficiency syndrome. Am J Surg. 1994 Sep;168(3): 244-6.

40 Janowitz P, Kratzer W, Zemmler T, Tudyka J, Wechsler JG. Gallbladder sludge: spontaneous course and incidence of complications in patients without stones. Hepatology. 1994 Aug;20(2):291-4.

41 Biank VF, Sheth MK, Talano J, Margolis D, Simpson P, Kugathasan S, et al. Association of Crohn's disease, thiopurines, and primary epstein-barr virus infection with hemophagocytic lymphohistiocytosis. J Pediatr. 2011 Nov;159(5):808-12.

42 Bergsten E, Horne A, Aricó M, Astigarraga I, Egeler RM, Filipovich AH, et al. Confirmed efficacy of etoposide and dexamethasone in HLH treatment: long-term results of the cooperative HLH-2004 study. Blood. 2017 Dec; 130(25):2728-38.
43 Li Y, Li CF, Zhang J, Xia XF, Zhou LY, Liu JJ, et al. Features of patients with inflammatory bowel diseases who develop hemophagocytic lymphohistiocytosis. Int J Colorectal Dis. 2016 Jul;31(7):1375-6.

44 Wang H, Xiong L, Tang W, Zhou Y, Li F. A systematic review of malignancy-associated hemophagocytic lymphohistiocytosis that needs more attentions. Oncotarget. $2017 \mathrm{Jul}$; 8(35):59977-85.

45 de Francisco R, Castaño-García A, MartínezGonzález S, Pérez-Martínez I, GonzálezHuerta AJ, Morais LR, et al. Impact of Epstein-Barr virus serological status on clinical outcomes in adult patients with inflammatory bowel disease. Aliment Pharmacol Ther. 2018 Oct;48(7):723-30.

46 Chapman S, El-Matary W. Screening for Epstein-Barr Virus Status and Risk of Hemophagocytic Lymphohistiocytosis in Children With Inflammatory Bowel Disease on Azathioprine. Gastroenterology. 2017 Oct; 153(4):1167-8.
47 Römkens TE, Bulte GJ, Nissen LH, Drenth JP. Cytomegalovirus in inflammatory bowel disease: A systematic review. World J Gastroenterol. 2016 Jan;22(3):1321-30.

48 Schwartz M, O'Brien C, Raya N, Reau N. Acquired Hemophagocytic Lymphohistiocytosis Associated With Disseminated Herpes Simplex Virus in Immunocompetent Host. ACG Case Rep J. 2019 Aug;6(8):e00164.

49 Liew JW, Jones BL, Hunter AJ. Disseminated Herpes Simplex Masquerading as Hemophagocytic Lymphohistiocytosis: A Case Report. Perm J. 2019;23:23.

50 Subramaniam K, D’Rozario J, Pavli P. Lymphoma and other lymphoproliferative disorders in inflammatory bowel disease: a review. J Gastroenterol Hepatol. 2013 Jan;28(1):2430. 